\title{
First photographic evidence of Asian Golden Cat Catopuma temminckii (Vigors and Horsfield, 1827) from Neora valley National Park, Central Himalayas, India
}

\author{
Paromit Chatterjee, Krishnendu Mondal*, Kailash Chandra, Basudev Tripathy \\ Zoological Survey of India, M - Block, New Alipore, Kolkata - 700053, West Bengal, India; drkrish31@gmail.com
}

\begin{abstract}
The Asiatic golden cat Catopuma temminckii also known as the Temminck's cat is a medium-sized wild cat distributed throughout South Asia. Asian Golden Cat is currently listed as Near Threatened in the IUCN Red List, and also listed in the Appendix I by CITES and Scheduled I in the Wildlife (Protection) Act, 1972 as the current population has been found to be declining due to habitat loss and poaching. It is a shy and elusive mammal, and very little information is available on its range, habitat and behaviour. The present study was conducted during the month of February and March 2017 as part of the Biodiversity assessment in the Indian Himalayan landscape through long-term monitoring protocol under the National Mission on Himalayan Studies, funded by the Ministry of Environment, Forest and Climate Change, Govt. of India. During the fieldwork in Neora Valley National Park, camera traps were deployed to record presence of mammals and ground birds. An Asian Golden Cat (Catopuma temminckii Vigors and Horsfield, 1827) was photo-captured in a single camera trap deployed in a trail in Thosum Beat of the Neora Valley National Park. The camera trap photograph confirmed the Asiatic Golden cat, presence in the National Park, and therefore, a long-term study in its probable habitats in South Asia may reveal its distribution, population status and ecology which will help towards long-term conservation of this species.
\end{abstract}

Keywords: Camera Trap, Darjeeling, Small Cat, Temperate Upper Hill Forest

Asian Golden Cat or Temminck's Cat is a medium-sized felid distributed in South-East Asia and one among the 15 felid species found in India (Lyngdoh et al., 2011; Menon, 2014; Gouda et al., 2016; Bashir et al., 2011; Dhendup, 2016). Despite of the knowledge gap on estimated population and density of this species across its geographical range, Asian Golden Cat is currently listed as Near Threatened in the IUCN Red List and listed in Appendix I by CITES as the current population is dwindling (McCarthy et al., 2015; Dhendup, 2016). It is also included under the Scheduled I in the Wildlife (Protection) Act, 1972 (Anonymous, 1972). Asian Golden Cat is a poorly studied species both in wild and captivity. Much of the information on various ecological aspects including habits ecology, social structure, and breeding behaviour is not known (Olsen, 2012).
Generally, the Asian golden cat looks similar to Puma concolor of America. They usually have an unmarked golden brown coat. Two distinctive mustache-like white stripes on the face and longitudinal markings on the forehead are present. The tail is long and not bushy (Menon, 2014; Grewal and Chakravarty, 2017). Asian Golden Cat shows various pelages in coat colour. There are four morphs that are known to science till date, such as common or normal, grey, melanistic and spotted (McCarthy et al., 2015; Dhendup, 2016). These pelage formations are considered to be local adaptations due to its diverse habitat use (Allen et al., 2011). Among these pelages, golden cats with melanistic pelages have been found to be occurring in the sub-alpine and alpine habitats of Central Himalayas in India (Bashir et al., 2011). The spotted pelages have been recorded from habitats viz.

\footnotetext{
* Author for correspondence
} 
dry deciduous forests, tropical savannas, grasslands etc. (Jutzeler et al., 2010).

\section{Study Area and Methods}

The Neora Valley National Park is situated in the recently declared Kalimpong district in the State of West Bengal, India (Figure 1). The total area of the park is $88 \mathrm{~km}^{2}$ (N26 $52^{\prime}-\mathrm{N} 27^{\circ} 7^{\prime} \& \mathrm{E} 88^{\circ} 45^{\prime}-\mathrm{E} 88^{\circ} 50^{\prime}$; altitudinal range 183 to $3200 \mathrm{~m}$ ) (Mallick 2010) and comes under the biogeographic zone $2 \mathrm{C}$ of the Central Himalayas, India (Rodgers et al. 1988; 2000). The park has three forest types along its altitudinal gradient, viz. a) Tropical lower hill forest, b) Subtropical middle hill forest and c) Temperate upper hill forest.

The present study was conducted during the month of February and March 2017 as a part of the project Biodiversity assessment in the Indian Himalayan landscape through long term monitoring protocol under the National Mission on Himalayan Studies of the Ministry of Environment, Forest and Climate Change, Govt. of India. During the field work at Neora Valley National
Park, camera traps (Cuddeback: X-Change Color, Model - 1279) were deployed to record the evidence of various species of mammals and ground birds in Neora Valley National Park. The forest type at the location where the camera trap was set had Sub-tropical Middle Hill Forest with dense canopies. Dominant tree species are Castanopis tribuloides, C. indica, Quercus sp, Sabia sp etc. The traps at each location were set for 3 consecutive nights.

\section{Results and Discussion}

Camera traps were placed at various locations inside the National Park on rotation basis to photo captures various animals present. An Asian Golden Cat was photo-captured in a single camera trap deployed in a trail in Thosum Beat inside the National Park (Mouchaki to Bhote Trail; N27 ${ }^{\circ} 02.139^{\prime}$ and E088 ${ }^{\circ} 46.730^{\prime}$; Elevation $1501 \mathrm{~m}$ ) on $28^{\text {th }}$ February, 2017 at 8:53 am (Figure 2). The photo-captured species was identified as an Asian Golden Cat-Normal Pelage (Catopuma temminckii Vigors and Horsfield, 1827) following Menon 2014, based on the characters depicted in the photo.

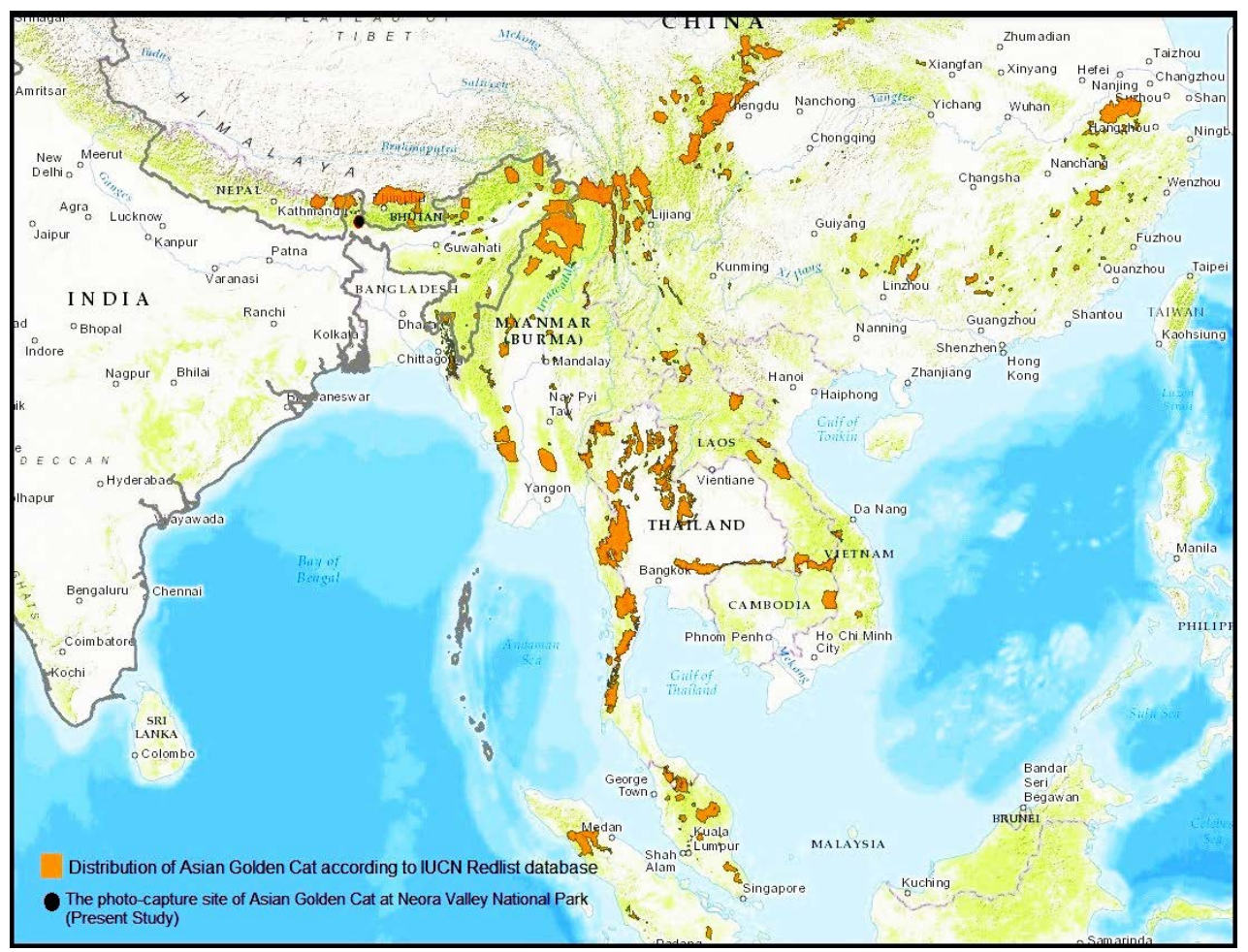

Figure 1. The distribution of Asian Golden Cat according to the IUCN Redlist database and the photo-capture site of the species from the present study at Neora Valley National Park, West Bengal, India. 


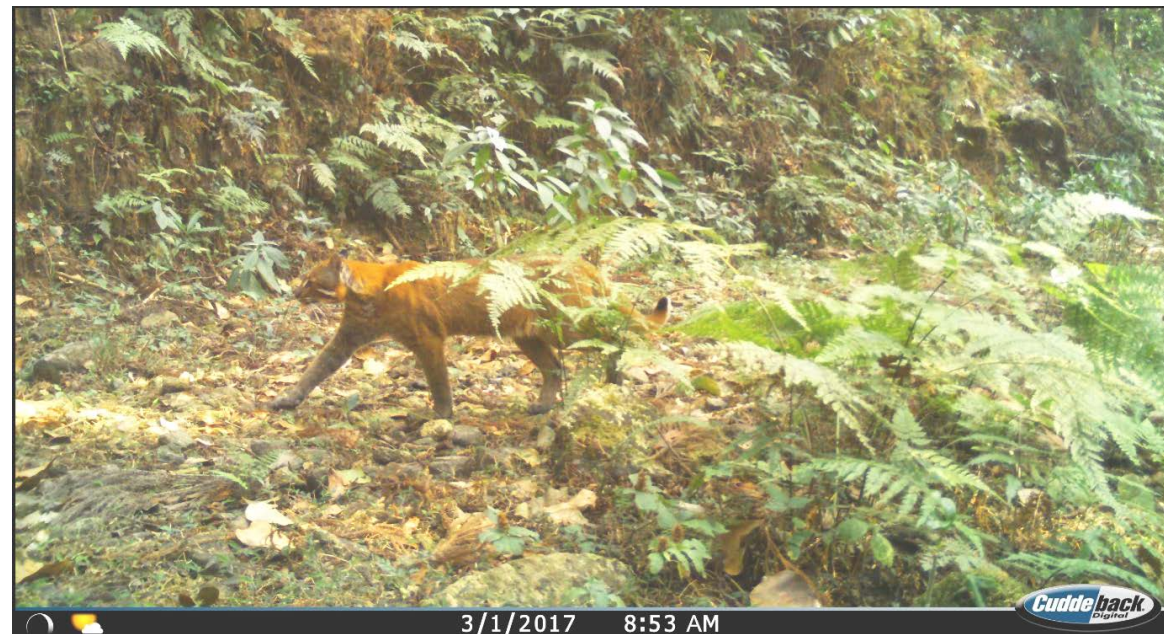

Figure 2. Camera Trap photograph of Asian golden cat (Catopuma temminckii Vigors \& Horsfield, 1827) captured in Neora Valley National Park, West Bengal, India.

According to IUCN Red list, current distribution of the Asian Golden Cat is only from Arunachal Pradesh, Assam, and Sikkim of India (McCarthy et al, 2015) and the State of West Bengal including the Neora Valley National Park is outside the distribution range of the species. However, distribution of Asian Golden Cat in the Darjeeling district (Gray, 1863) of Northern regions of West Bengal State is reported in the records of Zoological Survey of India (State Fauna Series, Series 13, Part -1), but no photographic evidence is supported in the literature. De et al., (2006) have also recorded this species from Arunachal Pradesh, Assam, Mizoram, Nagaland, Tripura, West Bengal and Sikkim of India based on secondary sources of information i.e., pugmarks and interview of the local forest inhabitants. Therefore, the distribution map of IUCN Red list has not showed the distribution of the study species in the Neora Valley National Park in West Bengal may be due to lack of proper evidence. Nevertheless, this species has been previously reported from the forests of Arunachal Pradesh (Datta et al., 2008, Lyngdoh et al., 2011), Sikkim (Biswas and Ghose, 1982; Bashir et al., 2011), Assam (Choudhury, 2007) and Mizoram (Gouda et al., 2016) and also recorded from the neighbour country of Bhutan (Wang, 2007; Jigme, 2011; Tempa et al., 2011; 2013; Thinley et al., 2015) and Nepal (Ghimirey and Pal, 2009). The present report confirms the presence of Asian Golden Cat in the Neora Valley National park of West Bengal for the first time with a photographic evidence. More study is certainly required in the Neora Valley National Park including surrounding Himalayan hills in West Bengal for better understanding of the distribution of this species and their habitat requirements.

Asian Golden Cat is known to be active during midmorning and late evening. Some studies define Asian golden cat as both crepuscular and diurnal (Grassman et al., 2005; Jigme, 2011; Thinley et al., 2015; Vernes et al., 2015; Dhendup, 2016). This felid species has been found to inhabit a wide range of habitats and their occurrence is not related with seasonality (Thinley et al., 2015). Moreover, all the morphs of this species has been found to occur at different altitudes as well as in different vegetation types, with the exception of Bhutan, where all the morphs were recorded from the same locality (Dhendup, 2016).

Through the recent molecular studies, it is suggested, that two sub-species of Asian golden cat occurs due to geographical separation (Luo et al., 2014; Patel et al. 2016). Indo-Chinese Population of Asian Golden Cats has been found to be different from the Malaysian/Sumatran population, however, due to lack of further scientific knowledge, the Indian population of the Catopuma temminckii has not been found to be different from the Chinese populations (Luo et al., 2014; Patel et al., 2016). Earlier, sub species of Asian Golden Cat has also been classified based on its pelage (Wilson and Reeder, 2005). Molecular studies on the taxonomy of Asian Golden Cat have however found only two sub species to be existing (Table 1). 
Table 1. Distribution of the subspecies of Asian Golden Cat, after (Patel et al., 2016)

\begin{tabular}{|l|l|l|l|l|}
\hline Sl No & Genus & Species & Sub Species & Countries \\
\hline 1 & Catopuma & temminckii & moormensis & $\begin{array}{l}\text { North-East India, Nepal, Tibet, China, Myanmar, Lao, } \\
\text { Cambodia, and Thailand }\end{array}$ \\
\hline 2 & Catopuma & temminckii & temminckii & Peninsular Malaysia and Sumatra \\
\hline
\end{tabular}

Since the present record is based only on photographic evidence, the identification is, therefore, restricted only to its species level. More studies using molecular DNA based tools are needed to confirm the sub species of the Asian Golden Cat in the Neora Valley National Park. Asian golden cat is chiefly a forest dependent species (McCarthy et al, 2015) and threatened due to habitat loss (Holden, 2001) and illegal poaching for its meat, pelt and body parts which are used for Chinese traditional medicine (Myers, 2016). Since there is no specific study conducted on Asian golden cat in Indian Sub-continent, no information is available on its population status, density and other ecological aspects. An immense knowledge gap exists even on the range of this species. A detailed and long-term study in its probable habitats in South Asia may reveal its actual occurrence and distribution.

\section{Acknowledgements}

The study is part of NMHS program (Grant number: NMHS/LG-2016/0011/8509 dated 31 ${ }^{\text {st }}$ March 2016) funded by MoEF and CC, India and therefore authors are thankful to MoEF and CC for the funding support. The authors are also thankful to West Bengal Forest Department for the necessary permissions and place on record the help of Mr. S.S. Giri, Range Officer of Samsing, Neora Valley National Park, Kalimpong, West Bengal during the field work. The authors are also thankful to Mr. Dibyajyoti Ghosh and Pritam Kumar Dey of ZSI, Kolkata for their support during the field work.

\section{References}

Allen, W.L., Cuthill, I.C., Scott-Samuel, N.E. and Baddeley, R. 2010. Why the leopard got its spots: relating pattern development to ecology in felids. Proceedings of the Royal Society of London B: Biological Sciences, rspb20101734.

Anonymous. 1972. Wildlife (Protection) Act, 1972, ed. Government of India. New Delhi.

Bashir, T., Bhattacharya, T., Poudyal, K. and Sathyakumar, S. 2011. Notable observations on the melanistic Asiatic Golden cat (Pardofelis temminckii) of Sikkim, India. NeBIO, 2(1): 2-4.

Biswas, B. and Ghose, R.K. 1982. Progress report 1 on 'Pilot Survey'of the World Wildlife Fund-India/Zoological Survey of India collaborative project on the 'Status Survey of the Lesser Cats in Eastern India' (Project No. IUCN 1357-India). Calcutta, 1-52. Published by Zool. Surv. India.

Choudhury, A. 2007. Sighting of Asiatic golden cat in the grasslands of Assam's Manas National Park. Cat News, 47: 29.

Datta, A., Anand, M.O. and Naniwadekar, R. 2008. Empty forests: Large carnivore and prey abundance in Namdapha National Park, north-east India. Biol Cons., 141(5): 1429-1435.

Dhendup, T. 2016. Status of Asiatic Golden Cat Catopuma temminckii Vigors \& Horsfield, 1827 (Carnivora: Felidae) in Bhutan. JoTT., 8(4): 8698-8702.

De, J. K., Mandal, A. K. and Ghosh, M. K. 2006. Mammals, Fauna of Arunachal Pradesh. State Fauna Series, 13 (Part 1): $21-68$. Published by Zool. Surv. India.

Ghimirey, Y. and Pal, P. 2009. First camera trap image of Asiatic golden cat in Nepal. Cat News, 51: 19.

Gouda, J., Sethy, J. and Chauhan, N. P. S. 2016. First photo capture of Asiatic golden cat in Dampa Tiger Reserve, Mizoram, India. Cat News, 64: 26-27.

Grassman, L.I., Tewes, M.E., Silvy, N.J. and Kreetiyutanont, K. 2005. Ecology of three sympatric felids in a mixed evergreen forest in north-central Thailand. J Mammal., 86(1): 29-38.

Gray, J. E. 1863. Catalogue of the specimens and drawings of Mammalia and birds of Nepal and Tibet present by B. H. Hodgson Esq. (2nd Ed), London. British Museum (Nat. Hist).

Jutzeler, E., Xie, Y. and Vogt, K. 2010. Asiatic golden cat in China. Cat News Special, (5): 40-41.

Shepherd, C.R. and Grewal, B. 2016. A Naturalist's Guide to the Mammals of India: 1-176, Published by John Beaufoy Publishing Ltd. Holden, J. 2001. Small cats in Kerinci Seblat National Park, Sumatra, Indonesia. Cat News, 35: 11-14.

Jigme, K. 2011. Four Colour Morphs of and the Altitudinal Record of Asiatic Golden Cat in Bhutan. Cat News, 55: 12-13. 
Luo, S.J., Zhang, Y., Johnson, W.E., Miao, L., Martelli, P., Antunes, A. Smith, J.L. and O’Brien, S.J. 2014. Sympatric Asian felid phylogeography reveals a major Indochinese-Sundaic divergence. Mol Ecol., 23(8): 2072-2092.

Lyngdoh, S., Selvan, K.M., Gopi, G.V. and Habib, B. 2011. First photographic evidences of two rare cats from Pakke Tiger Reserve, western Arunachal Pradesh. Curr. Sci., 101(10): 1284-1286.

McCarthy, J., Dahal, S., Dhendup, T., Gray, T.N.E., Mukherjee, S., Rahman, H., Riordan, P., Boontua, N. and Wilcox, D. 2015. Catopuma temminckii. The IUCN Red List of Threatened Species 2015: e. T4038A50651004.

Menon, V. 2014. Indian mammals: a field guide: 1-200, Published by Hachette India.

Myers, S. 2016. Wildlife of Southeast Asia: 1-256, Published by Princeton University Press.

Olsen, D. 2012. Introduction of Asiatic golden cat Catopuma temminckii at Taronga Conservation Society Australia. International Zoo Yearbook, 46(1): 201-208.

Patel, R.P., Förster, D.W., Kitchener, A.C., Rayan, M.D., Mohamed, S.W., Werner, L., Lenz, D., Pfestorf, H., Kramer-Schadt, S., Radchuk, V. and Fickel, J. 2016. Two species of Southeast Asian cats in the genus Catopuma with diverging histories: an island endemic forest specialist and a widespread habitat generalist. Royal Soc. Open Sci, 3(10): 160350.

Tempa, T., Hebblewhite, M., Mills, L.S., Wangchuk, T.R., Norbu, N., Wangchuk, T., Nidup, T., Dendup, P., Wangchuk, D., Wangdi, Y. and Dorji, T. 2013. Royal Manas National Park, Bhutan: a hot spot for wild felids. Oryx, 47(2): 207-210.

Tempa, T., Norbu, N., Dhendup, P. and Nidup, T. 2011. Results from a camera trapping exercise for estimating tiger population size in the lower foothills of Royal Manas National Park. Ugyen Wangchuck Institute for Conservation and Environment and Royal Manas National Park, Royal Government of Bhutan, Lamai Gompa.

Thinley, P., Morreale, S.J., Curtis, P.D. and Lassoie, J.P. 2015. Diversity, occupancy, and spatio-temporal occurrences of mammalian predators in Bhutan's Jigme Dorji National Park. Bhutan J. Nat. Res. Dev., 2(1): 19-27.

Vernes, K., Sangay, T., Rajaratnam, R. and Singye, R. 2015. Social Interaction and co-occurrence of colour morphs of the Asiatic Golden Cat, Bhutan. Cat News, 62: 18-20.

Wang, S.W. 2007. A rare morph of the Asiatic golden cat in Bhutan's Jigme Singye Wangchuck National Park. Cat News, 47: 27-28.

Wilson, D.E. and Reeder, D.M. (Eds.). 2005. Mammal species of the world: a taxonomic and geographic reference, 1-2142, Published by JHU Press. 